\title{
Dietary pattern is associated with obesity in Chinese children and adolescents: data from China Health and Nutrition Survey (CHNS)
}

Shihan Zhen, Yanan Ma, Zhongyi Zhao, Xuelian Yang and Deliang Wen *i)

\begin{abstract}
Background: Associations of dietary patterns in Chinese adolescents and children with later obesity have not previously been investigated. The purpose of the present study was to evaluate the associations between dietary patterns and the risk of obesity in Chinese adolescents and children by using a longitudinal design.

Methods: Data from the China Health and Nutrition Survey (CHNS), a nationally representative survey, were used for our analysis. 489 participants 6-14 years of age were followed from 2006 to 2011 . Factor analysis was used to identify the dietary patterns in Chinese adolescents and children. Ordered logistic regression models were used to examine the association between dietary patterns and later obesity.

Results: Two dietary patterns were revealed by factor analysis, the traditional Chinese dietary pattern (with high intake of rice, vegetables, poultry, pork and fish and the modern dietary pattern (with high intake of wheat, processed meat and fast food). Children in the highest quartile and the second-highest quartile of the traditional Chinese dietary pattern was inversely associated with later obesity compared with children in the lowest quartile over 5 years ( $\mathrm{OR}=0.19,95 \% \mathrm{Cl}: 0.09,0.40$ for Q4; $\mathrm{OR}=0.47,95 \% \mathrm{Cl}: 0.33,0.67$ for Q3); Children in the highest quartile of the modern dietary pattern was positively associated with later obesity compared with children in the lowest quartile over 5 years $(\mathrm{OR}=2.02,95 \% \mathrm{Cl}: 1.17,3.48)$.

Conclusions: Dietary patterns in Chinese adolescents and children are associated with later obesity. These findings further confirm the importance of children's dietary patterns in later obesity and lay groundwork for dietary culturespecific interventions targeted at reducing rates of obesity in children and adolescents.
\end{abstract}

Keywords: Dietary patterns, Obesity, China, Adolescents, Children

\section{Background}

Childhood overweight and obesity have become a worldwide health problem. In developing countries, Childhood overweight and obesity have increased at an alarming rate $[1,2]$. In 2014, about 35 million children were affected by overweight or obesity, and the prevalence of overweight and obesity for children in China was 12.2 and $7.3 \%$ respectively [1]. These large increases in the prevalence of childhood obesity might greatly increase morbidity in adulthood from causes such as cardiovascular

\footnotetext{
* Correspondence: dlwen@cmu.edu.cn

China Medical University, No.77 Puhe Road, Shenyang North New Area,

Shenyang, Liaoning Province, China
}

disease, metabolic syndrome and diabetes [3-5]. Therefore, research identifying risk factors of childhood obesity are needed to address this severe public health problem.

Obesity is caused by an intricacy interaction among the environment, genetics and behavior [6]. Among these factors, diet has been demonstrated to be a determinant in the development of obesity [7]. However, owing to the complexity of diets and the potential associations between dietary components [8], the relationship between diet and obesity is intricate and barely understood [9]. Compared with traditional dietary analyses focusing on individual foods or nutrients [10],

(c) The Author(s). 2018 Open Access This article is distributed under the terms of the Creative Commons Attribution 4.0 International License (http://creativecommons.org/licenses/by/4.0/), which permits unrestricted use, distribution, and 
dietary pattern analysis might be an alternative holistic and comprehensive approach [11].

Dietary pattern analysis take advantage of complex diet, take into account multiple food groups instead of individual foods or nutrients, and can reveal potential interactions between various nutrients and food $[11,12]$. Consequently, dietary pattern analysis might reflect the complexity of dietary intake and provide new insights into what people eat $[13,14]$. Thus, dietary pattern analysis has widely been used to determine associations between diet and chronic diseases and to aid in formulating nutritional recommendations [15-17].

In China, transition of dietary patterns is an ongoing phenomenon [18]. Over the past 20 years, dietary patterns have transitioned from a traditional diet to a modern diet with high intake of refined grains and meat; the abundance of energy-dense food in the modern diet is cause for concern [13]. Dramatic changes in dietary patterns may explain the increase in obesity among children and adolescents [19]. However, to our knowledge, most previous studies have followed a cross-sectional design $[15,20]$ and have focused primarily on adults [21, 22]. Few studies have analyzed the long-term effects of dietary patterns and obesity in Chinese children or adolescents. Therefore, in the present study, we sought to characterize dietary patterns at baseline and to identify the associations between dietary patterns and later obesity in Chinese children and adolescents by using a longitudinal study design.

\section{Methods}

\section{Study design and population}

In the present investigation, we used longitudinal data from the China Health and Nutrition Survey (CHNS), an open prospective cohort study. CHNS used a multistage random-cluster sampling process to select samples from 15 provinces in China [23]. CHNS was approved by the Institutional Review Committees of the University of North Carolina at Chapel Hill and the National Institute of Nutrition and Food Safety, Chinese Center for Disease Control and Prevention. Details have been described elsewhere [24].

We used the longitudinal data from 2006 to 2011. A total of 736 participants aged 6-14 were involved in 2006. Among them, 489 participants completed all three surveys and were enrolled in the current analysis. We excluded participants with implausibly high or low caloric intakes (ie, $<600$ or $>4000 \mathrm{kcal} / \mathrm{d}$ ), missing dietary pattern data or anthropometry data, or those with a history of metabolic disease before baseline.

\section{Dietary assessment and food grouping}

Details of dietary measurements have been provided elsewhere [25]. In brief, dietary were recorded through a 24-h-recall method for three consecutive days for each participant. For children younger than 12 years, parents were asked to recall children's food consumption. Alcoholic beverages were excluded because of very low consumption in children.

Dietary were based on the food frequency questionnaire using in the survey in 2006 . The dietary data were divided into 28 food groups (Table 1) based on their similarity in nutrients and Chinese Food Composition Table [26].

\section{Outcome variables}

Height and weight were measured by using a standardized protocol from the World Health Organization (WHO) [27] in which height is measured to the nearest $0.1 \mathrm{~cm}$, as participants stand with their backs against a wall, with no shoes and with their eyes looking straight ahead. Weight was measured according to the WHO protocol, with a lever balance to the neared $0.1 \mathrm{~kg}$, in participants wearing minimal undergarments and no shoes. Body mass index (BMI) was then calculated as weight (in kilograms) divided by squared height (in meters). Obesity was defined according to age and sex by using the WHO BMI growth reference [5-19] years.

\section{Covariates}

Covariates including age, sex, residency, highest level of parental education, region, physical activity and energy intake were collected by in-home visit interviews and general information questionnaires. Residency was classified into two categories (urban and rural), region was classified into three categories (western, eastern and central), highest level of parental education was classified into five categories (illiterate or primary school; middle school; high school; technical or vocational degree; and college or higher). Physical activity was calculated as duration of total physical activity and expressed in hours per week (hours/week). Energy intake was calculated according to the China Food Composition and expressed in kilocalories per day ( $\mathrm{kcal} /$ day).

\section{Statistical analysis}

Dietary patterns were identified at baseline (in 2006) by factor analysis using the principal component method. The factor scores were orthogonally (varimax) rotated to create less correlation among the patterns and to facilitate interpretability. An eigenvalue is the variance of the factor. In the initial factor solution, the first factor will account for the most variance, the second will account for the next highest amount of variance, and so on. According to the previous study $[16,28]$, dietary patterns were identified on the basis of the eigenvalue $(>2)$ and scree plot. Percentages of variances were also calculated. Factor loading of $>|0.20|$ was included to represent the 
Table 1 Food groupings used in factor analysis

\begin{tabular}{|c|c|}
\hline Food group & Examples of food items \\
\hline Rice & White and brown rice \\
\hline Wheat noodles & Wheat noodles \\
\hline Wheat flour & Wheat flour \\
\hline Wheat buns, breads & Bun, butter bread, salty bread \\
\hline Cakes, cookies and pastries & $\begin{array}{l}\text { Cookies, mooncake, fruit cake, } \\
\text { chocolate cake, fruit pie }\end{array}$ \\
\hline Deep-fried wheat & $\begin{array}{l}\text { Deep-fried dough stick, deep- } \\
\text { fried cake with red bean paste }\end{array}$ \\
\hline Corn and coarse grain & $\begin{array}{l}\text { Corn, corn grits, barley, oats, } \\
\text { foxtail millet, sorghum }\end{array}$ \\
\hline Starchy roots and tubers & $\begin{array}{l}\text { Potato, yam, taro, lotus root, } \\
\text { water chestnut, cassava }\end{array}$ \\
\hline Fresh legumes & $\begin{array}{l}\text { Soybean sprouts, peas with } \\
\text { pod, mung bean sprouts }\end{array}$ \\
\hline Dried legumes & $\begin{array}{l}\text { Soybean flour, dried beans, } \\
\text { beans flour, roasted broad bean }\end{array}$ \\
\hline Legume products & $\begin{array}{l}\text { Tofu, tofu products, red/mung } \\
\text { bean paste }\end{array}$ \\
\hline Nuts and seeds & $\begin{array}{l}\text { Sesame, sunflower, lotus seeds, } \\
\text { peanuts, walnuts, almonds, } \\
\text { hazelnuts, pine-nuts, pistachios, } \\
\text { cashew nuts }\end{array}$ \\
\hline Fresh vegetables, non-leafy & $\begin{array}{l}\text { Cauliflower, tomatoes, cucumber, } \\
\text { zucchini, mushrooms }\end{array}$ \\
\hline Fresh vegetables, leafy & Spinach, 'bok choy', cabbage \\
\hline Pickled and salted vegetables & $\begin{array}{l}\text { preserved vegetables, vegetables } \\
\text { in soy sauce }\end{array}$ \\
\hline Seaweed & Fresh or dried seaweed \\
\hline Fruits & $\begin{array}{l}\text { Fresh and canned (no added } \\
\text { sugar) fruits }\end{array}$ \\
\hline Red meat & beef, lamb, donkey, rabbit \\
\hline Pork & $\begin{array}{l}\text { Pork tenderloin, Pork belly, } \\
\text { leg, rib chop }\end{array}$ \\
\hline Organ meats & Liver, kidney, large intestine, blood \\
\hline Processed meats & $\begin{array}{l}\text { Sausages, ham, luncheon meat, } \\
\text { dried meat, smoked meat }\end{array}$ \\
\hline Poultry and game & Chicken, duck, goose \\
\hline Eggs and eggs and products & $\begin{array}{l}\text { Whole eggs, yolk, white, } \\
\text { preserved eggs }\end{array}$ \\
\hline Fish and seafood & $\begin{array}{l}\text { Fresh- and salt-water fish, dried } \\
\text { fish, shellfish }\end{array}$ \\
\hline Milk and dairy products & $\begin{array}{l}\text { Cow milk, goat milk, skim milk, } \\
\text { flavored milk, cheese, yogurt }\end{array}$ \\
\hline Fast food & $\begin{array}{l}\text { Onion rings, potato chips, Western- } \\
\text { style fast-food, salty snacks }\end{array}$ \\
\hline Candy & $\begin{array}{l}\text { Jelly, jam, chocolate, honey, } \\
\text { sugar, candies }\end{array}$ \\
\hline Sweetened beverages & $\begin{array}{l}\text { Fruit or flavored drinks, fruit } \\
\text { juice, soft drinks }\end{array}$ \\
\hline
\end{tabular}

The traditional Chinese dietary pattern was loaded heavily on rice, red meat, pork, poultry, vegetables (leafy) and fish. The modern dietary pattern was loaded heavily on wheat buns, cakes, legume products, nuts, pickled and salted vegetables, fruit, red meat, processed meats, poultry, eggs, fish, milk and fast food food strongly associated with the identified factor [29]. Pattern-specific factor scores were calculated as the sum of the food factor loading coefficients and the standardized daily consumption of food related to the dietary pattern. Factor scores were divided into four quartiles on the basis of their contribution to each pattern, and an increase from Q1 to Q4 was assumed.

ANOVA tests for continuous variables and chi-square tests for categorical variables were used to compare the different quartiles in dietary patterns at baseline. Ordered logistic regression models were used to estimate the odds ratios (OR) and 95\% confidence intervals (95\%CI) for later childhood obesity across the quartile categories of dietary pattern score. Model 1 was adjusted for sex and age. Model 2 was additionally adjusted for residency, highest level of parental education, region, physical activity and energy intake. Model 3 additionally used a cluster analysis to reduce the spatial interdependence, which can adversely affect the robustness of regression estimates [30]; we used the classifications of geographical regions as cluster groups to analyze the association.

To gain access to the full sample, we used the multiple imputation technique to fill in the missing values ten times, a procedure suggested to be sufficient in a previous study [31]. Imputation was performed by using multivariate normal regression. A $p$-value $<0.05$ was regarded as statistically significant. All analyses were performed in Stata (version 13.0; StataCorp, College Station, TX, USA).

\section{Results}

Examples of food items for each food group are shown in Table 1. The baseline characteristics of participants, according to quartiles for each dietary pattern, are shown in Table 2. At baseline, 37 participants (7.57\%) were overweight, while 56 participants (11.45\%) had obesity. Participants in the highest quartile of the traditional dietary pattern were more likely to be significantly older, live in the central of China, had a lower prevalence of obesity and higher energy intake than those in the lowest quartile. Conversely, participants in the highest quartile of the modern dietary pattern were more likely to live in urban, eastern of China, had a higher parental education level and higher energy intake than those in the lowest quartile $(p<0.05)$.

Two dietary patterns were determined in the present study. The factor loading of each pattern is shown in Table 3. The traditional Chinese dietary pattern (Eigenvalue $=2.36$ ) was loaded heavily on rice, red meat, pork, poultry, vegetables (leafy) and fish, and was inversely loaded on wheat flour, wheat buns, vegetables (non-leafy), corn and eggs. The modern dietary pattern (Eigenvalue $=$ 
Table 2 Baseline characteristics of participants according to quartiles of dietary patterns

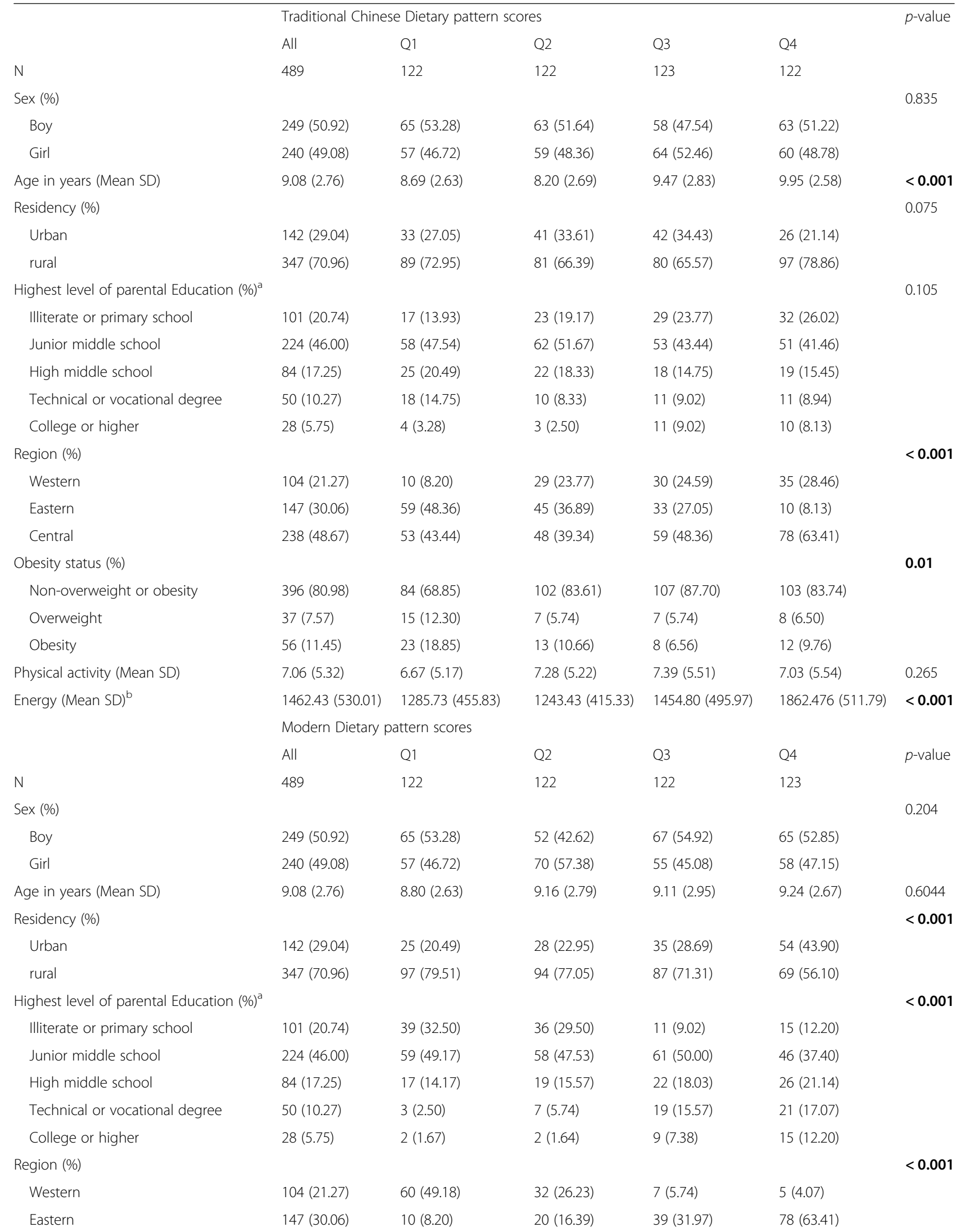


Table 2 Baseline characteristics of participants according to quartiles of dietary patterns (Continued)

\begin{tabular}{|c|c|c|c|c|c|c|}
\hline Central & $238(48.67)$ & $52(42.62)$ & $70(57.38)$ & $76(62.3)$ & $40(32.52)$ & \\
\hline Obesity status (\%) & & & & & & 0.208 \\
\hline Non-overweight or obesity & $396(80.98)$ & $108(88.52)$ & $99(81.15)$ & $94(77.05)$ & $95(77.24)$ & \\
\hline Overweight & $37(7.57)$ & $3(2.46)$ & $10(8.20)$ & $12(9.84)$ & $12(9.76)$ & \\
\hline Obesity & $56(11.45)$ & $11(9.02)$ & $13(10.66)$ & $16(13.11)$ & $16(13.01)$ & \\
\hline Physical activity (Mean SD) & $7.06(5.32)$ & $7.33(5.78)$ & $6.90(5.39)$ & $7.02(5.18)$ & $7.01(5.03)$ & 0.797 \\
\hline Energy (Mean SD) ${ }^{\mathrm{b}}$ & $1462.43(530.01)$ & $1325.28(461.8118)$ & $1386.38(488.41)$ & $1461.66(552.026)$ & $1674.66(550.73)$ & $<0.001$ \\
\hline
\end{tabular}

$p$-value was calculated from $x^{2}$ test for binary variables or by ANOVA for continuous variables. Dietary patterns were identified at baseline (in 2006 ). $p$-values $<0.05$ are bold. ${ }^{a}: n=487$ cause of the missing data. ${ }^{b}: n=435$ cause of the missing data

Table 3 Factor loadings for dietary patterns derived from exploratory factor analysis

\begin{tabular}{|c|c|c|}
\hline & Traditional pattern & Modern pattern \\
\hline Rice & 0.7401 & \\
\hline Wheat noodles & & -0.2918 \\
\hline Wheat flour & -0.4377 & \\
\hline Wheat buns, breads & -0.5472 & 0.2077 \\
\hline Cakes, cookies and pastries & & 0.4780 \\
\hline \multicolumn{3}{|l|}{ Deep-fried wheat } \\
\hline Corn and coarse grain & -0.3337 & \\
\hline \multicolumn{3}{|l|}{ Starchy roots and tubers } \\
\hline \multicolumn{3}{|l|}{ Fresh legumes } \\
\hline \multicolumn{3}{|l|}{ Dried legumes } \\
\hline Legume products & & 0.3734 \\
\hline Nuts and seeds & & 0.4711 \\
\hline Fresh vegetables, non-leafy & -0.2290 & \\
\hline Fresh vegetables, leafy & 0.6119 & \\
\hline Pickled and salted vegetables & & 0.2529 \\
\hline \multicolumn{3}{|l|}{ Seaweed } \\
\hline Fruits & & 0.5154 \\
\hline Red meat & 0.2667 & 0.2245 \\
\hline Pork & 0.4855 & \\
\hline \multicolumn{3}{|l|}{ Organ meats } \\
\hline Processed meats & & 0.3149 \\
\hline Poultry and game & 0.2555 & 0.3335 \\
\hline Eggs and eggs products & -0.3168 & 0.3282 \\
\hline Fish and seafood & 0.2524 & 0.4346 \\
\hline Milk and dairy products & & 0.4770 \\
\hline Fast food & & 0.4726 \\
\hline \multicolumn{3}{|l|}{ Candy } \\
\hline Sweetened beverages & & \\
\hline
\end{tabular}

Dietary patterns were identified at baseline (in 2006). Absolute values $<0.20$ are excluded from the table for simplicity
2.22) was loaded heavily on wheat buns, cakes, legume products, nuts, pickled and salted vegetables, fruit, red meat, processed meats, poultry, eggs, fish, milk and fast food, and was inversely loaded on wheat noodles. The two patterns together explained $16.36 \%$ of the dietary intake variance.

The relationship between dietary patterns and later obesity in each wave, as assessed with the ordered logistic model, is displayed in Tables 4 and 5, respectively. In Table 4, dietary patterns were identified at baseline (in 2006), whereas participants' obesity status was measured in 2009. In 2009, after cluster analysis and adjustment for confounders, children in the highest quartile (Q4) of the traditional Chinese dietary pattern had lower odds of obesity (OR $=0.29,95 \% \mathrm{CI}$ : $0.16,0.51$ for Q4) than those in the lowest (Q1), whereas children in Q4, Q3 and Q2 of the modern dietary pattern had greater odds of obesity than those in Q1 $(\mathrm{OR}=3.22,95 \% \mathrm{CI}: 1.66,6.23$ for $\mathrm{Q} 4 ; \mathrm{OR}=2.46,95 \% \mathrm{CI}$ : 2.17, 2.80 for $\mathrm{Q} 3 ; \mathrm{OR}=2.22$, 95\%CI: 1.42, 3.46 for Q2). Moreover, in Table 5, participants' obesity status were measured in 2011, children in Q4 and Q3 of the traditional Chinese dietary pattern still had lower odds of obesity $(\mathrm{OR}=0.19,95 \% \mathrm{CI}$ : $0.09,0.40$ for Q4; OR $=0.47,95 \% \mathrm{CI}$ : 0.33, 0.67 for Q3) than those in Q1, whereas children in Q4 of the modern dietary pattern still had greater odds of obesity $(\mathrm{OR}=2.02$, 95\%CI: 1.17, 3.48) than those in Q1.

\section{Discussion}

In the present study, we report analysis of dietary patterns among Chinese children aged 6-14 at baseline and the association of dietary patterns with later obesity. Two dietary patterns were identified in the multicenter longitudinal study that satisfactorily captured eating habits ( $16.36 \%$ of dietary intake variance explained). The first pattern, the traditional Chinese dietary pattern, was characterized mainly by high consumption of rice, vegetables, pork, red meat, poultry and fish. The second pattern, the modern dietary pattern, consisted of a 
Table 4 Multivariable adjusted ORs and 95\%Cl for obesity in 2009 across quartiles of dietary pattern scores

\begin{tabular}{|c|c|c|c|c|c|}
\hline & \multicolumn{5}{|c|}{ Traditional Chinese Dietary pattern } \\
\hline & Q1 & Q2 & Q3 & Q4 & $P$ for trend \\
\hline Model1 & 1 & $0.87(0.43,1.75)$ & $0.60(0.29,1.28)$ & $0.34(0.14,0.82)$ & 0.010 \\
\hline Model2 & 1 & $1.04(0.52,2.10)$ & $0.66(0.31,1.41)$ & $0.29(0.10,0.78)$ & 0.015 \\
\hline \multirow[t]{3}{*}{ Model3 } & 1 & $1.04(0.54,2.00)$ & $0.66(0.31,1.40)$ & $0.29(0.16,0.51)$ & 0.002 \\
\hline & \multicolumn{5}{|c|}{ Modern Dietary Pattern } \\
\hline & Q1 & Q2 & Q3 & Q4 & $P$ for trend \\
\hline Model1 & 1 & $2.09(0.84,5.20)$ & $2.47(1.01,6.07)$ & $3.18(1.33,7.64)$ & 0.009 \\
\hline Model2 & 1 & $2.22(0.87,5.63)$ & $2.46(0.99,6.14)$ & $3.22(1.26,8.18)$ & 0.018 \\
\hline Model3 & 1 & $2.22(1.42,3.46)$ & $2.46(2.17,2.80)$ & $3.22(1.66,6.23)$ & 0.006 \\
\hline
\end{tabular}

Model 1: adjusted for sex and age. Model 2: additionally adjusted for residency, highest level of parental education, region, physical activity and energy intake. Model 3: additionally included use of classifications of geographical regions as cluster groups to analyze the association. Dietary patterns were identified at baseline (in 2006). $p$-value for trend was obtained by adjusting the quartiles of the pattern scores as a continuous variable. $p$-values $<0.05$ are bold

combination of wheat buns, bread, cake, cookies, legumes, pickled (salted) vegetables, fruits, nuts, red meat, processed meat, poultry, eggs, fish, milk and fast food. The identified "traditional" and "modern" dietary patterns are similar to those reported previously conducted among adults in China [16, 17, 21].

In the present study, the traditional Chinese dietary pattern was inversely associated with later obesity, whereas the modern dietary pattern was positively associated with later obesity. Our results are comparable to those of previous studies. The Dutch Lifelines cohort study indicated that the healthier dietary pattern which have high intake of fruit, vegetables and fish were inversely associated with obesity, whereas the modern dietary pattern which have high intake of bread, potatoes and sweet snacks had a significantly increased risk of obesity [32]. In a 6-year prospective study conducted in UK, Ambrosini et al. [33] also reported that a dietary pattern high in meat, energy density and fat might be positively associated with obesity. However, previous studies have mainly focused on adults [22, 23] and cross-sectional designed $[16,21]$. Some findings relating dietary patterns and obesity may not be applicable to Chinese adolescents and children, owing to cultural factors affecting intake.

Overall, the present results suggested that the traditional Chinese dietary pattern may be protective against later obesity. The protective effect may be attributed to its healthful components. For example, the benefit of consuming whole grains, vegetables and legumes as part of the traditional Chinese dietary pattern may explain the protective effect in our study [16, 22]. First, rice, an essential staple food in China, is a low-energy food that constitutes the bulk of the traditional Chinese diet. Energy density of rice is lower than that of wheat [15]. Different methods are used in cooking rice and wheat. Steamed rice contains twice the amount of water and half the energy content as an equivalent amount of bread [22]. Second, instead of organ and processed meats, the traditional Chinese dietary pattern includes a

Table 5 Multivariable adjusted ORs and 95\%Cl for obesity in 2011 across quartiles of dietary pattern scores

\begin{tabular}{|c|c|c|c|c|c|}
\hline & \multicolumn{5}{|c|}{ Traditional Chinese Dietary Pattern } \\
\hline & Q1 & Q2 & Q3 & Q4 & $P$ for trend \\
\hline Model1 & 1 & $1.00(0.52,1.95)$ & $0.52(0.24,1.12)$ & $0.28(0.11,0.70)$ & 0.002 \\
\hline Model2 & 1 & $1.06(0.54,2.08)$ & $0.47(0.21,1.02)$ & $0.19(0.070 .49)$ & $<0.001$ \\
\hline \multirow[t]{3}{*}{ Model3 } & 1 & $1.06(0.30,3.69)$ & $0.47(0.33,0.67)$ & $0.19(0.09,0.40)$ & $<0.001$ \\
\hline & \multicolumn{5}{|c|}{ Modern Dietary Pattern } \\
\hline & Q1 & Q2 & Q3 & Q4 & $P$ for trend \\
\hline Model1 & 1 & $1.30(0.56,3.06)$ & $1.67(0.75,3.77)$ & $2.17(0.99,4.77)$ & 0.039 \\
\hline Model2 & 1 & $1.28(0.54,3.01)$ & $1.58(0.69,3.65)$ & $2.02(0.88,4.65)$ & 0.086 \\
\hline Model3 & 1 & $1.28(0.48,3.44)$ & $1.58(0.74,3.39)$ & $2.02(1.17,3.48)$ & 0.078 \\
\hline
\end{tabular}

Model 1: adjusted for sex and age. Model 2: additionally adjusted for residency, highest level of parental education, region, physical activity and energy intake. Model 3: additionally included use of classifications of geographical regions as cluster groups to analyze the association. Dietary patterns were identified at baseline (in 2006). $p$-value for trend was obtained by adjusting the quartiles of the pattern scores as a continuous variable. $p$-values $<0.05$ are bold 
high intake of white meat, fish and seafood, which are all associated with a low prevalence of obesity. Fish has been found to be protective against obesity because of its omega-3 polyunsaturated fatty acid content [34]. White meat has less fat than red meat, and the fats present are primarily healthful unsaturated fats [31, 35]. Another potential explanation for our findings may be vegetable intake. Vegetables that provide large amounts of dietary fiber, antioxidants (e.g., vitamins $\mathrm{C}$ and $\mathrm{E}$ ) and water may contribute to decreasing the risk of later obesity $[16,36]$. However, in the present study, fresh leafy and non-leafy vegetables showed opposite effects in factor loadings. We assumed that the different cooking methods using in preparing vegetables might explain the opposite effects. For instance, stir-frying non-leafy vegetables in vegetable oil may increase energy density [22, 37].

The present study also found a higher risk of obesity associated with the modern dietary pattern. Previous studies have shown positive associations between modern dietary patterns abundant in saturated fat and cholesterol $[16,38,39]$ and a higher risk of obesity. The associations between the modern dietary pattern and later obesity may be attributed to the high amounts of suboptimal foods together with the lower fiber intake $[29,33,40]$. Wheat gluten may promote weight gain, partly by decreasing the thermogenic capacity of adipose tissue [21]. Second, high consumption of red meat and processed meat, containing amounts of saturated fat and cholesterol, is directly associated with an increased risk of obesity [16, 35, 41]. Another characteristic of the modern pattern is the use of the unhealthful cooking method deep-frying [37]. Consumption of deep-fried fast food, such as potato chips and deep-fried dough, is of serious concern. A prospective cohort study has suggested that greater consumption of fried food is associated with a higher risk of obesity in follow-up [42]. Additionally, in this study, we found that milk and dairy products were positively associated with the modern pattern score. A previous study has suggested that milk intake associated with risk of childhood obesity, and the insulinotropic and IGF-1-raising effects of milk and dairy products may have further adverse effects on obesity [43]. Moreover, excess energy intake may play a role in the development of obesity [44]. After adjustment for energy intake, we found that the associations for each dietary pattern remained significant.

To our knowledge, this is the first study reporting the relations between dietary patterns and later obesity risk among the children and adolescents in China. Our findings provided valuable information for the primary prevention of childhood obesity through the dietary modifications in a Chinese children and adolescents. However, it is important to note some potential limitations. Firstly, the present study was limited by old data source and small sample sizes (here we report 489 participants) which may not necessarily representative of the general Chinese populations. Second, there was a high rate of loss of subjects to follow-up because of migration and city construction. However, there was no significant difference between those lost in follow-up and those retained. Thus, the association between dietary patterns and the risk of later obesity might not have been biased. Thirdly, dietary data were collected through three 24-h dietary recalls, which might not represent long-term usual intake, and using a baseline dietary data might provide a biased estimate. Fourthly, some subjective and arbitrary decisions should be considered, including the number of factors retained and the labeling of dietary patterns. However, these aspects are common to factor analyses, and the methodology has been validated and found satisfactory [22]. Finally, even though we controlled for many covariates, there are still some potential socioeconomic and genetic factors that may have confounded our estimation.

\section{Conclusion}

In conclusion, the present study identified two dietary patterns among Chinese adolescents and children aged 6-14 years at baseline: the traditional Chinese pattern and the modern pattern. The traditional Chinese dietary pattern was inversely associated with later obesity, whereas the modern dietary pattern was positively associated with later obesity. These findings further confirmed the importance of dietary patterns among children in later obesity and lay a groundwork for culture-specific interventions targeted at reducing rates of childhood obesity. Interventions aiming at discouraging the adoption of the modern dietary pattern, such as consumption of fried food, processed meat, and energy-dense foods, while encouraging the traditional Chinese dietary pattern, should be developed.

\begin{abstract}
Acknowledgements
This research uses data from China Health and Nutrition Survey (CHNS). We thank the National Institute for Nutrition and Health, China Center for Disease Control and Prevention, Carolina Population Center (P2C HD050924, T32 HD007168), the University of North Carolina at Chapel Hill, the NIH (R01-HD30880, DK056350, R24 HD050924, and R01-HD38700) and the NIH Fogarty International Center (D43 TW009077, D43 TW007709) for financial support for the CHNS data collection and analysis files from 1989 to 2015 and future surveys, and the China-Japan Friendship Hospital, Ministry of Health for support for CHNS 2009, Chinese National Human Genome Center at Shanghai since 2009, and Beijing Municipal Center for Disease Prevention and Control since 2011.
\end{abstract}

\section{Funding \\ This work was supported by the National Natural Science Foundation of China [71774173].}

\section{Availability of data and materials}

The data that support the findings of this study are available from The China Health and Nutrition Survey, but restrictions apply to the availability of these data, which were used under license for the current study, and so are not publicly available. Data are however available from the authors upon reasonable request and with permission of The China Health and Nutrition Survey. 


\section{Authors' contributions}

SZ analyzed and interpreted the data, and was a major contributor in writing the manuscript. YM explained the data regarding the relationship between dietary pattern and obesity. ZZ analyzed the data regarding the relationship between dietary pattern and obesity. XY analyzed the data regarding the relationship between dietary pattern and obesity. DW made substantial contributions to design the study. All authors read and approved the final manuscript.

\section{Ethics approval and consent to participate}

Data of this study was from the China Health and Nutrition Survey (CHNS). CHNS was approved by the Institutional Review Committees of the University of North Carolina at Chapel Hill and the National Institute of Nutrition and Food Safety, Chinese Center for Disease Control and Prevention.

\section{Consent for publication}

Not applicable.

\section{Competing interests}

The authors declare that they have no competing interests.

\section{Publisher's Note}

Springer Nature remains neutral with regard to jurisdictional claims in published maps and institutional affiliations.

\section{Received: 11 March 2018 Accepted: 26 June 2018}

\section{Published online: 11 July 2018}

\section{References}

1. Ng M, Fleming T, Robinson M, Thomson B, Graetz N, Margono C, Mullany EC, Biryukov S, Abbafati C, Abera SF, et al. Global, regional and national prevalence of overweight and obesity in children and adults 1980-2013: a systematic analysis. Lancet. 2014;384:766-81.

2. Jia P, Xue H, Zhang J, Wang Y. Time trend and demographic and geographic disparities in childhood obesity prevalence in China-evidence from twenty years of longitudinal data. Int J Environ Res Public Health. 2017;14(4):369

3. Lloyd LJ, Langley-Evans SC, McMullen S. Childhood obesity and risk of the adult metabolic syndrome: a systematic review. Int J Obes. 2012:36:1-11.

4. Doyon A, Schaefer F. The prodromal phase of obesity-related chronic kidney disease: early alterations in cardiovascular and renal function in obese children and adolescents. Nephrol Dial Transplant : official publication of the European Dialysis and Transplant Association - European Renal Association. 2013;28(Suppl 4):iv50.

5. Liang Y, Hou D, Zhao X, Wang L, Hu Y, Liu J, Cheng H, Yang P, Shan X, Yan $Y$. Childhood obesity affects adult metabolic syndrome and diabetes. Endocrine. 2015;50:87.

6. Yanovski JA. Pediatric obesity. An introduction. Appetite. 2015;93:3-12.

7. Keast DR, Hill Gallant KM, Albertson AM, Gugger CK, Holschuh NM. Associations between yogurt, dairy, calcium, and vitamin D intake and obesity among U.S. children aged 8-18 years: NHANES, 2005-2008. Nutrients. 2015;7:1577-93.

8. DeClercq V, Cui Y, Forbes C, Grandy SA, Keats M, Parker L, Sweeney E, Yu ZM, Dummer TJB. Association between diet quality and adiposity in the Atlantic PATH cohort. Nutrients. 2017;9(10):1155.

9. Popkin BM, Adair LS, Ng SW. NOW AND THEN: the global nutrition transition: the pandemic of obesity in developing countries. Nutr Rev. 2012; 70:3-21.

10. Boeing H, Bechthold A, Bub A, Ellinger S, Haller D, Kroke A, Leschik-Bonnet E, Müller MJ, Oberritter H, Schulze M, et al. Critical review: vegetables and fruit in the prevention of chronic diseases. Eur J Nutr. 2012;51:637-63.

11. Van HL: Eating pattern analyses: the whole is more than the sum of its parts. J Am Diet Assoc 2011, 111:203-203.

12. Tucker KL. Dietary patterns, approaches, and multicultural perspective. Applied physiology, nutrition, and metabolism = Physiologie appliquee, nutrition et metabolisme. 2010;35:211.

13. Batis C, Sotres-Alvarez D, Gordon-Larsen P, Mendez MA, Adair L, Popkin B. Longitudinal analysis of dietary patterns in Chinese adults from 1991 to 2009. Br J Nutr. 2014;111:1441-51.
14. Moeller SM, Reedy J, Millen AE, Dixon LB, Newby PK, Tucker KL, Krebs-Smith SM, Guenther PM. Dietary patterns: challenges and opportunities in dietary patterns research an experimental biology workshop, April 1, 2006. Journal of the American Dietetic Association. 2007:107:1233-9.

15. Shang X, Li Y, Liu A, Zhang Q, Hu X, Du S, Ma J, Xu G, Li Y, Guo H. Dietary pattern and its association with the prevalence of obesity and related Cardiometabolic risk factors among Chinese children. PLoS One. 2012;7: e43183-e43183.

16. Shu L, Shen XM, Li C, Zhang XY, Zheng PF. Dietary patterns are associated with type 2 diabetes mellitus among middle-aged adults in Zhejiang Province, China. Nutr J. 2017;16:81.

17. Melaku YA, Gill TK, Appleton SL, Taylor AW, Adams R, Shi Z. Prospective associations of dietary and nutrient patterns with fracture risk: a 20-year follow-up study. Nutrients. 2017;9.

18. Popkin BM. Synthesis and implications: China's nutrition transition in the context of changes across other low and middle income countries. Obes Rev. 2014;15(01):60-67.

19. Balthazar EA, de Oliveira MRM. Differences in dietary pattern between obese and eutrophic children. BMC Res Notes. 2011:4:567.

20. Chan R, Chan D, Lau W, Lo D, Li L, Woo J. A cross-sectional study to examine the association between dietary patterns and risk of overweight and obesity in Hong Kong Chinese adolescents aged 10-12 years. J Am Coll Nutr. 2014:33:450

21. Yuan YQ, Li F, Meng P, You J, Wu M, Li SG, Chen B. Gender difference on the association between dietary patterns and obesity in Chinese middleaged and elderly populations. Nutrients. 2016;8(8):448.

22. Shi Z, Yuan B, Hu G, Dai Y, Zuo H, Holmboe-Ottesen G. Dietary pattern and weight change in a 5-year follow-up among Chinese adults: results from the Jiangsu nutrition study. Br J Nutr. 2011;105:1047.

23. Popkin BM, Du S, Zhai F, Zhang B. Cohort profile: the China health and nutrition survey-monitoring and understanding socio-economic and health change in China, 1989-2011. Int J Epidemiol. 2010;39:1435-40.

24. Xu X, Byles JE, Shi Z, Hall JJ. Evaluation of older Chinese people's macronutrient intake status: results from the China health and nutrition survey. Br J Nutr. 2015;113:159.

25. Zhai F, Du S, Wang Z, Zhang J, Du W, Popkin B. Dynamics of the Chinese diet and the role of Urbanicity, 1991-2011. Obes Rev. 2014;15

26. Yang YX. China food composition. In: Beijing Peking University medical press; 2005

27. Eveleth PB. Physical status: the use and interpretation of anthropometry. Report of a WHO Expert Committee. World Health Organization Technical Report. 1995;854:1.

28. Shu L, Zheng PF, Zhang XY, Si CJ, Yu XL, Gao W, Zhang L, Liao D. Association between dietary patterns and the indicators of obesity among Chinese: a cross-sectional study. Nutrients. 2015;7:7995-8009.

29. Xu X, Hall J, Byles J, Shi Z. Dietary pattern is associated with obesity in older people in China: data from China health and nutrition survey (CHNS). Nutrients. 2015;7:8170-88.

30. Petersen MA. Estimating standard errors in finance panel data sets: comparing approaches. Nber Working Papers. 2005;22:435-80.

31. Rubin DB, Schenker N. Multiple imputation in health-care databases: an overview and some applications. Stat Med. 2010;10:585-98.

32. Slagter SN, Corpeleijn E, van der Klauw MM, Sijtsma A, Swart-Busscher LG, Perenboom CWM, de Vries JHM, Feskens EJM, Wolffenbuttel BHR, Kromhout D, van Vliet-Ostaptchouk JV. Dietary patterns and physical activity in the metabolically (un)healthy obese: the Dutch lifelines cohort study. Nutr J. 2018;17:18.

33. Ambrosini GL. Tracking a dietary pattern associated with increased adiposity in childhood and adolescence. obesity. 2014;22:458-65.

34. Lorente-Cebrián S, Costa AG, Navas-Carretero S, Zabala M, Martínez JA, Moreno-Aliaga MJ. Role of omega-3 fatty acids in obesity, metabolic syndrome, and cardiovascular diseases: a review of the evidence. Journal of Physiology \& Biochemistry. 2013;69:633-51.

35. Cocate PG, Natali AJ, De OA, Alfenas RC, Peluzio MC, Longo GZ, dos Santos EC, Buthers JM, de Oliveira LL, Hermsdorff HH. Red but not white meat consumption is associated with metabolic syndrome, insulin resistance and lipid peroxidation in Brazilian middle-aged men. Eur J Prev Cardiol. 2015;22:223.

36. Buckland G, Bach A, Serra-Majem L. Obesity and the Mediterranean diet: a systematic review of observational and intervention studies. Obesity Reviews An Official Journal of the International Association for the Study of Obesity. 2008;9:582. 
37. Sayonorea C, Carlos S, Martínezgonzalez MA. Does cooking with vegetable oils increase the risk of chronic diseases?: a systematic review. $\mathrm{Br} J$ Nutr. 2015;113(Suppl 2):S36.

38. Naja F, Hwalla N, Itani L, Karam S, Mehio Sibai A, Nasreddine L. A western dietary pattern is associated with overweight and obesity in a national sample of Lebanese adolescents (13-19 years): a cross-sectional study. Br J Nutr. 2015;114:1909-19.

39. Vergnaud AC, Norat T, Romaguera D, Mouw T, May AM, Travier N, Luan J, Wareham N, Slimani N, Rinaldi S. Meat consumption and prospective weight change in participants of the EPIC-PANACEA study. Am J Clin Nutr. 2010;92:398-407.

40. Pala V, Lissner L, Hebestreit A, Lanfer A, Sieri S, Siani A, Huybrechts I, Kambek L, Molnar D, Tornaritis M. Dietary patterns and longitudinal change in body mass in European children: a follow-up study on the IDEFICS multicenter cohort. Eur J Clin Nutr. 2013;67:1042-9.

41. Rouhani MH, Salehi-Abargouei A, Surkan PJ, Azadbakht L. Is there a relationship between red or processed meat intake and obesity? A systematic review and meta-analysis of observational studies. Obesity Reviews An Official Journal of the International Association for the Study of Obesity. 2014;15:740-8.

42. Sayon-Orea C, Bes-Rastrollo M, Basterra-Gortari FJ, Beunza JJ, GuallarCastillon P, De IF-AC, Martinez-Gonzalez MA. Consumption of fried foods and weight gain in a Mediterranean cohort: the SUN project. Nutr Metab Cardiovasc Dis. 2013;23:144-50.

43. Melnik BC. Milk-the promoter of chronic western diseases. Med Hypotheses. 2009;72:631-9.

44. Mendoza JA, Watson K, Cullen KW. Change in dietary energy density after implementation of the Texas public school nutrition policy. J Am Diet Assoc. 2010;110:434-40.

Ready to submit your research? Choose BMC and benefit from:

- fast, convenient online submission

- thorough peer review by experienced researchers in your field

- rapid publication on acceptance

- support for research data, including large and complex data types

- gold Open Access which fosters wider collaboration and increased citations

- maximum visibility for your research: over $100 \mathrm{M}$ website views per year

At BMC, research is always in progress.

Learn more biomedcentral.com/submissions 